\title{
The Impact of Resection Margins on the Overall and Disease-free Survival of Hepatic Colorectal Metastases
}

\author{
Antonio Zanghi ${ }^{1}$, Andrea Cavallaro ${ }^{1}$, Sebastiano Mongiovì ${ }^{2}$, Maria Di Vita ${ }^{1}$, Chiara Rapisarda ${ }^{1}$, \\ Francesco Cardi ${ }^{1}$, Alessia Giaquinta ${ }^{3}$, Emanuele Lo Menzo ${ }^{4}$, Alessandro Cappellani ${ }^{1}$
}

'Department of Surgery, General Surgery and Breast Unit, University of Catania, Italy ${ }^{2}$ General Surgery, Humanitas Oncology Center, Catania, Italy

${ }^{3}$ Vascular Surgery and Organ Transplant Unit, Department of Surgery

University Hospital of Catania, Italy

${ }^{4}$ Emanuele Lo Menzo, Cleveland Clinic Florida, Weston, USA

\section{ABSTRACT}

Background: Liver resection for colorectal liver metastasis (CRLM) represents a valid therapeutic option. It can offer a chance of good long-term survival, with a 5 year survival of 25- $40 \%$. Recent studies have shown that achieving a minimum of $1 \mathrm{~cm}$ surgical margin is not essential for long-term survival, and a microscopic free liver resection margin can be sufficient. The aim of this study is to evaluate the impact of the resection margin on recurrence, disease free survival and the overall survival.

Materials and Method: All the primary liver resections with curative intention for CRLM at our surgical division between 2000 and 2010 were retrospectively reviewed. The liver resection margins were stratified according to their width. The positive and negative prognostic factors were analyzed in a univariate analysis.

Results: A total of 130 patients met the study inclusion criteria. Twenty-four patients underwent major hepatectomies, while 106 patients underwent minor hepatectomies. On statistical analysis, surgical margin width $(p=0.045)$, advanced age $(p<0.001)$, metachronous metastasis $(p=0.018)$ and multiple tumours $(p=0.019)$ were associated with lower long-term survival rates. In addition, advanced age $(p=0.0004)$, rectal tumour $(p=0.004)$, metachronous metastases $(p=0.026)$, multiple tumours $(p=0.017)$, lower width in surgical margin $(p=0.002)$ were linked to a reduced disease-free survival.

Conclusion: Our study confirms that the extent of the resection margin is a powerful factor influencing prognosis after hepatectomy for CRLM. According to our experience, resection margin width is significantly associated with a higher risk of intra and extra-hepatic recurrence and less disease-free survival. However, the impossibility of achieving a resection margin greater than or equal to $10 \mathrm{~mm}$ should not be considered as a contraindication to surgery.

Key words: hepatic resection, margins, width. liver metastases, histologic measurement, colon, rectum, colorectal, cancer

\section{INTRODUCTION}

Liver resection for colorectal liver metastasis (CRLM) can offer a chance of good long-term survival, with 5 -year survival rates of $25-40 \%$ having been reported in the literature (1-5).

\author{
Corresponding author: \\ Andrea Cavallaro, MD, PhD \\ Department of Surgery \\ General Surgery and Breast Unit \\ University of Catania \\ Via S. Sofia 78, 95123 Catania, Italy \\ Telephone: +39-95-3781228 \\ Fax: +39-95-3782912 \\ E-mail: andreacavallaro@tiscali.it
}


Dukes stage, preoperative serum concentration of carcinoembryonic antigen (CEA), size and number of liver metastases, as well as disease-free interval between resection of the primary tumour and diagnosis of liver metastases are commonly considered the most relevant prognostic factors affecting long term survival after liver resection. The extent of surgical resection margin remains, however, a controversial topic.

Several studies showed that a resection margin of less than $1 \mathrm{~cm}$ liver for CRLM is a poor prognostic factor, as it is associated with a higher rate of intrahepatic disease recurrence (6-8). For this reason, the surgical inability of achieving a margin of $1 \mathrm{~cm}$ was considered a contraindication to liver resection in many centers $(3,9-11)$.

Recent studies have shown that achieving a surgical margin of at least $1 \mathrm{~cm}$ is not essential for long-term survival (12-13). Consequently, many authors, even more recently, advocate for liver resection in any case, as long as the surgical margin is free from microscopic disease (14-15).

The aim of this study is to evaluate the impact of the resection margin, stratified according to its width, on recurrence, disease free survival and the overall survival.

\section{MATERIALS AND METHODS}

Between 2000 and 2010, all patients who underwent primary liver resection for CRLM with curative intent in two surgical units were retrospectively reviewed. The data was obtained by retrospective review of clinical records and recent follow up was provided by patients or their care-givers' telephone contact.

The following aspects were collected for each patient: demographics, primary tumour location, tumour biology, nodal involvement, size, number and distribution of metastases, type of metastasis (synchronous or metachronous), disease-free interval (between primary tumour resection and liver metastasis diagnosis) in the case of metachronous metastases, type of liver resection, and preoperative CEA.

The surgical resection margin was defined as the minimum distance between the transection area and the nearest lesion of the resected specimen.

Before each surgical procedure, every patient underwent a thorough medical history, physical examination, abdominal ultrasound and computer tomography, and/or magnetic resonance.

Patients were considered candidates for hepatectomy when it was possible to perform a $\mathrm{RO}$ resection, leaving a sufficient volume of functional residual liver (at least 30\% non-tumoural parenchyma).

Liver resections were defined according to the Couinaud's anatomic classification of the liver (16).

The resection of 3 or more liver segments and complex liver resections (such as caudate lobe resection) were classified as major hepatectomy.

The width of the resection margin was either measured during an intraoperative pathological examination on a frozen section and reported in the database or evaluated from the final pathological report. Microscopically, the resection margin invaded by the disease was classified as positive (R1 resection), while the disease-free margin was classified as negative (RO resection). Negative resection margins were divided into 4 subgroups according to their width:

- $1^{\text {st }}$ subgroup: $\leq 2.99 \mathrm{~mm}$;

- $2^{\text {nd }}$ subgroup: $3 \mathrm{~mm}-4.99 \mathrm{~mm}$;

- $3^{\text {rd }}$ subgroup: $5 \mathrm{~mm}-9.99 \mathrm{~mm}$;

- $4^{\text {th }}$ subgroup: $\geq 10 \mathrm{~mm}$.

The pattern of the metastatic recurrence was subdivided into extrahepatic or hepatic, and the site of liver recurrence was classified as "surgical margin" or "other intrahepatic site".

The positive and negative prognostic factors were analysed in a statistical analysis.

The overall survival rate and the disease-free survival rate were calculated using the Kaplan-Meier method. The chi-square test was used to compare the proportions. The significance level was defined as $p$ less than 0.05. The Statistical Analysis was conducted using In-Silico Statistical Calculators and SPSS 16.0.

\section{RESULTS}

Out of a total of 210 patients who underwent primary hepatectomy with curative intent for CRLM at the P.O. Gaspare Rodolico of Catania and at Catania Humanitas Oncology Center, 130 were included in this study. Eighty patients were excluded from the study: 61 patients because of lacking follow up data, and 19 patients because they did not consent to the use of personal data. There were 77 males (59.23\%) and 53 women $(40.77 \%)$, with a mean age of 65 years (range 35 to 85 years). The primary tumour was originating from the colon in 80 patients and from the rectum in the remaining 50 . Forty-two patients $(33.08 \%)$ had synchronous liver metastases, whereas 87 (66.92\%) presented metachronous lesions. The mean number of CRLMs was 2 (range 1 - 15), with 42 patients (33.08\%) presenting single liver lesions, and $87(66.92 \%)$ having 
multiple ones. The mean size of the CRLM was $2.06 \pm$ $1.35 \mathrm{~cm}$.

Fifty-two patients underwent major hepatectomies while seventy-eight patients underwent minor hepatectomy liver resections, performed by removing less than three liver segments. The number, size, and intrahepatic localization did not affect the resection potential. A positive surgical margin was observed in the pathological examination in 5 patients (3.84\%). RO liver resection was performed in 125 patients (96.16\%). The preoperative evaluation of serum CEA was not available in all patients. Only 66 patients $(50.76 \%)$ in the study received neoadjuvant chemotherapy treatment.

The characteristics of the 130 patients are summarized in table 1.

The overall survival rate at 5 years was $32.30 \%$, while the 5-year disease free survival rate was $25.38 \%$. The mean survival was 21 months. Sixty-six (50.7\%) patients had recurrence during the first year after resection, 17 (13\%) patients developed recurrence during the second year, while 46 (35.3\%) patients had recurrence afterwards.

The statistical analysis of the free margin in relation to survival and disease-free interval is described hereafter. Many biological and technical factors have been tested for predicting global and disease-free survival rates (tables $2 a-b$ ).

Patients were divided into two groups: patients with tumour infiltration or residual microscopic disease (R1 hepatic resection), which is $3.85 \%$ of the total number of patients, and patients with no microscopic residual disease and no tumour infiltration (RO hepatic resection).

Patients with R0 hepatic resection were stratified according to margin size: margin greater than or equal to $10 \mathrm{~mm}$ (57.9\% of patients), 5-9.99 mm (12.3\% of patients), $3-5.99 \mathrm{~mm}$ (16.15\% of patients), less than or equal to $2 \mathrm{~mm}$ (10\% of patients).

The overall survival rate at 5 years was $32.30 \%$, while the 5 -year disease free survival rate was $25.38 \%$. The rate of recurrence is inversely correlated to the size of the surgical margin.

On univariate analysis, surgical margin width ( $p=$ $0.045)$, advanced age ( $p<0.001)$, metachronous metastases ( $p=0.018)$, multiple tumour $(p=0.019)$ were associated with lower long-term survival rates.

In addition, advanced age ( $p=0.0004)$, rectal tumor $(p=0.004)$, metachronous metastases $(p=0.026)$, multiple tumours $(p=0.017)$ and lower width of surgical margin are related to a reduced disease free-survival.

In patients with $\mathrm{R} 1$ resections, overall survival rates

Table 1 - Patient Characteristics

\begin{tabular}{|c|c|c|}
\hline Age (years), mean \pm DS (range) & $65 \pm 9(35-85)$ & \\
\hline Number of men/woman & $77 / 53$ & \\
\hline Site of primary tumor, number of patients (\%) & & $\%$ \\
\hline colon & 80 & 61,54 \\
\hline rectum & 50 & 38,46 \\
\hline Nodal involvement, number of patients(\%) & & $\%$ \\
\hline yes & 79 & 60,77 \\
\hline no & 50 & 38,46 \\
\hline unknown & 1 & 0,77 \\
\hline Preoperative CEA level, $\mathrm{ng} / \mathrm{ml}$, mean & $225,53 \mathrm{ng} / \mathrm{ml}$ & \\
\hline Type of metastases, number of patients (\%) & & $\%$ \\
\hline synchronous & 43 & 33,08 \\
\hline metachronous & 87 & 66,92 \\
\hline Size of the tumor $(\mathrm{cm})$, mean \pm DS & $2,06 \pm 1,35 \mathrm{~cm}$ & \\
\hline Tumor size, mean (range) & $2(1-15)$ & \\
\hline \multicolumn{3}{|l|}{ Tumor number } \\
\hline single, number $(\%)$ & 77 & 59,23 \\
\hline multiple, number (\%) & 53 & 40,77 \\
\hline \multicolumn{3}{|c|}{ Type of surgical procedures, number of patients (\%) } \\
\hline minor resection & 78 & 60,00 \\
\hline major resection & 52 & 40,00 \\
\hline
\end{tabular}


Table 2 a - Statistical analysis: overall survival

Table 2 b - Statistical analysis: disease free survival

\begin{tabular}{|c|c|c|c|c|c|c|c|c|}
\hline & $\begin{array}{c}\text { number } \\
\text { (130) }\end{array}$ & $\begin{array}{c}\text { 5-years } \\
\text { survival (42) }\end{array}$ & $\begin{array}{c}\text { 5-years } \\
\text { survival (\%) }\end{array}$ & $P$ value & $\begin{array}{c}\text { number } \\
(130)\end{array}$ & $\begin{array}{c}\text { 5-years } \\
\text { disease free (34) }\end{array}$ & $\begin{array}{c}\text { 5-years } \\
\text { disease free (\%) }\end{array}$ & $P$ value \\
\hline age & & & & $<0,0001$ & & & & 0.0004 \\
\hline$>60$ years & 92 & 19 & 20,65 & & 92 & 16 & 17,39 & \\
\hline$\leq 60$ years & 38 & 23 & 60,53 & & 38 & 18 & 47,37 & \\
\hline site of primary tumor & & & & 0.9527 & & & & 0.0045 \\
\hline colon & 80 & 26 & 32,50 & & 50 & 20 & 40,00 & \\
\hline rectum & 50 & 16 & 32,00 & & 80 & 14 & 17,50 & \\
\hline primary tumor nodes & & & & 0.9664 & & & & 0.7433 \\
\hline node + & 79 & 25 & 31,65 & & 79 & 21 & 26,58 & \\
\hline node - & 50 & 16 & 32,00 & & 50 & 12 & 24,00 & \\
\hline unknown & 1 & 1 & 100,00 & & 1 & 1 & 100,00 & \\
\hline type of metastases & & & & 0.0188 & & & & 0.0261 \\
\hline synchronous & 43 & 8 & 18,60 & & 43 & 6 & 13,95 & \\
\hline metachronous & 87 & 34 & 39,08 & & 87 & 28 & 32,18 & \\
\hline disease free interval & & & & 0.6847 & & & & 0.2152 \\
\hline$\leq 12$ months & 33 & 12 & 36,36 & & 33 & 8 & 24,24 & \\
\hline$>12$ months & 54 & 22 & 40,74 & & 54 & 20 & 37,04 & \\
\hline CEA preoperative level & & & & 0.9309 & & & & 0.5064 \\
\hline$\leq 50 \mathrm{ng} / \mathrm{ml}$ & 59 & 18 & 30,51 & & 59 & 15 & 25,42 & \\
\hline$>50 \mathrm{ng} / \mathrm{ml}$ & 17 & 5 & 29,41 & & 17 & 3 & 17,65 & \\
\hline unknown & 54 & 19 & 35,19 & & 54 & 16 & 29,63 & \\
\hline tumor size & & & & 0.2558 & & & & 0.8572 \\
\hline$\leq 5 \mathrm{~cm}$ & 112 & 39 & 34,82 & & 112 & 32 & 28,57 & \\
\hline$>5 \mathrm{~cm}$ & 3 & 2 & 66,67 & & 3 & 1 & 33,33 & \\
\hline unknown & 15 & 1 & 6,67 & & 15 & 1 & 6,67 & \\
\hline tumor number & & & & 0.0194 & & & & 0.0173 \\
\hline single & 77 & 31 & 40,26 & & 77 & 26 & 33,77 & \\
\hline multiple & 53 & 11 & 20,75 & & 53 & 8 & 15,09 & \\
\hline number of metastases & & & & 0.2156 & & & & 0.1845 \\
\hline$\leq 3$ lesions & 114 & 39 & 34,21 & & 114 & 32 & 28,07 & \\
\hline$>3$ lesions & 16 & 3 & 18,75 & & 16 & 2 & 12,50 & \\
\hline extent of liver resection & & & & 0.4959 & & & & 0.5685 \\
\hline major hepatectomy & 52 & 18 & 34,62 & & 52 & 15 & 28,85 & \\
\hline minor hepatectomy & 78 & 24 & 30,77 & & 78 & 19 & 24,36 & \\
\hline surgical margin status & & & & 0.0455 & & & & 0.0026 \\
\hline R1 resection & 5 & 0 & - & & 5 & 0 & - & \\
\hline \multicolumn{9}{|l|}{ R0 resection } \\
\hline$\leq 2,99 \mathrm{~mm}$ & 13 & 1 & 7,69 & & 13 & 0 & - & \\
\hline $3-4,99 \mathrm{~mm}$ & 21 & 4 & 19,05 & & 21 & 1 & 4,76 & \\
\hline $5-9,99 \mathrm{~mm}$ & 16 & 6 & 37,50 & & 16 & 5 & 31,25 & \\
\hline$\leq 10 \mathrm{~mm}$ & 75 & 31 & 41,33 & & 75 & 28 & 37,33 & \\
\hline
\end{tabular}

${ }^{*} \mathrm{P}$-value $=$ chi - squared test according to Pearson

at 5 years and disease-free survival are, in both cases, 0 .

In our experience, the width of the surgical margin continues to have a significant impact on overall and disease-free interval (1).
Figures 1 and 2 show the rates of overall and disease-free survival, respectively, for patients with RO resection, stratified according to the width of the surgical margin. 


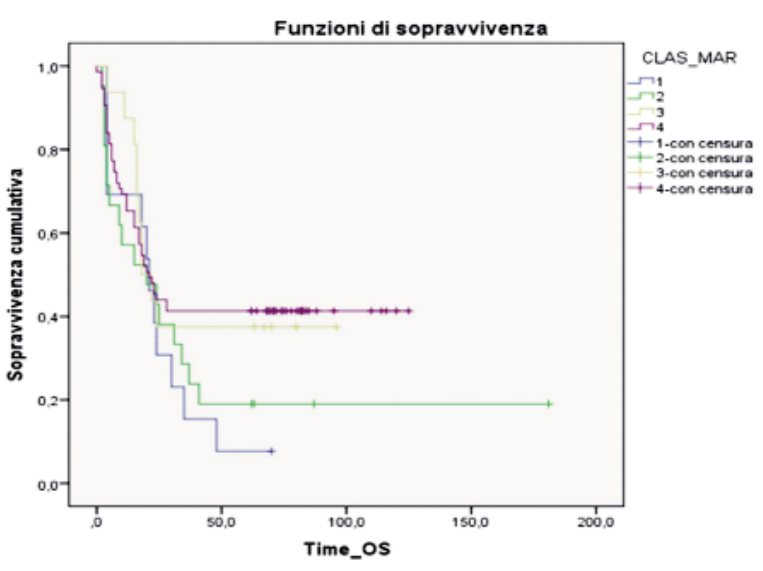

Figure 1 - Time_0S $=$ 0verall survival

\section{Pathological and clinical characteristics of patients with $R 0$ resection}

125 patients (96.15\%) experienced a RO resection:

- 13 patients $(10 \%)$ with margin $\leq 2.99 \mathrm{~mm}$;

- 21 patients $(16.15 \%)$ with a margin of $3-4.99$ $\mathrm{mm}$;

- 16 patients $(12.30 \%)$ with a margin of $5-9.99$ $\mathrm{mm}$;

- 75 patients $(57,69 \%)$ with a margin of $\geq 10 \mathrm{~mm}$.

The characteristics of the four classes are summarized in table 3.

The evaluation of parameters for each margin width class confirmed the predominant role of the resection margin width on the disease-free margin.

\section{DISCUSSION}

Hepatic resection is still commonly defined as the only treatment able to offer a long-term survival opportunity in patients with CRLM (1). Literature reports an increase in survival from $7.7 \%$ to $41.33 \%$ after resection. It is important to remember that neoadjuvant chemotherapy has been increasingly used over the years; new chemotherapeutic drugs, such as oxaliplatin, irinotecan, bevacizumab have recently been introduced with promising results (2).

In the past 20 years, a multitude of studies have investigated the prognostic significance of several clinical and pathological factors in patients who had undergone hepatic resection of colorectal metastases. Among all factors, width of resection margin is an important variable, only partially depending upon the surgeon. In many circumstances the distance between the metastasis and the bilio-vascular structures that

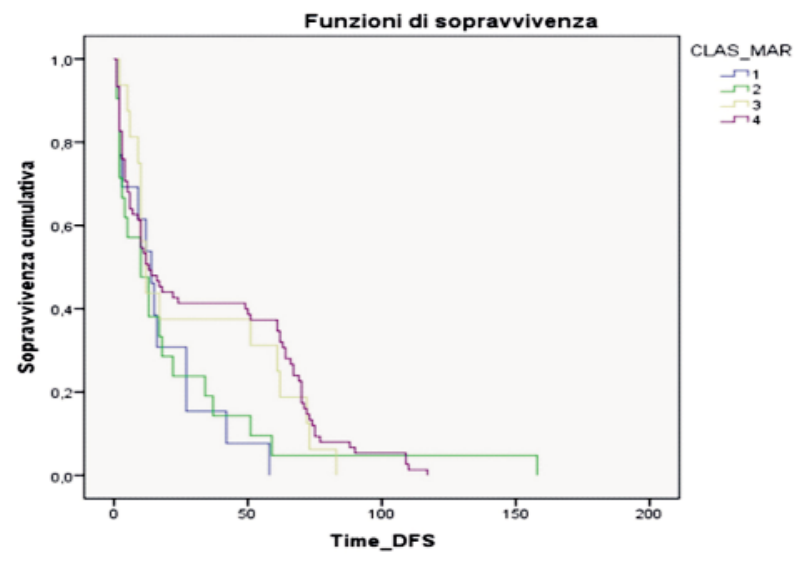

Figure 2 - Time_DFS = disease-free-survival

have be preserved for the planned hepatectomy prevents the surgeon from obtaining a wide margin. This is becoming a routine scenario in the era of complex liver resections of multiple and bilateral liver metastases, often down-staged to surgery after neoadjuvant chemotherapy. Several studies have shown that such complex hepatectomies are associated with a higher risk of close resection margins (1-3).

\section{RO vs RI}

Many authors have shown that a positive resection margin after hepatectomy for CRLM is associated with a higher incidence of recurrence and lower survival rates $(3,8,10,12,17-19)$.

Yamamoto et al. (1999) have shown that a R1 surgical margin had an adverse effect on survival. However, due to the fact that it was strongly associated with the number of resected metastases, it was not an independent prognostic factor in multivariate analysis (17).

Conversely, Hamady et al. (2006) have shown that a positive surgical margin is an independent factor of poor survival in multivariate analysis (18).

Patients with a positive margin often have other adverse biological factors and the cause of their poor long-term survival is still unclear. (17-19).

Margonis GA et al (2015) stratified 332 patients who underwent CRLM liver resection in three groups based on their margin status: R0, R1, and R1 $\rightarrow$ R0 conversion. Differences in median survival, recurrence rates and patterns were not significant between the three groups $(P>0.05)$. The authors conclude that in the era of modern systemic chemotherapy, it seems that the impact of margin status on outcomes may be minimal compared to that of patient and tumour factors. In this 
Table 3 - Pathological and clinical characteristics of the different RO groups

\begin{tabular}{|c|c|c|c|c|c|c|c|c|c|}
\hline & $\begin{array}{l}\leq 2,99 \mathrm{~mm} \\
13 \text { patients) }\end{array}$ & $\%$ & $\begin{array}{l}3-4,99 \mathrm{~mm} \\
\text { (21 patients) }\end{array}$ & $\%$ & $\begin{array}{l}5 \text { - 9,99 mm } \\
\text { (16 pazients) }\end{array}$ & $\%$ & $\begin{array}{c}\geq 10 \mathrm{~mm} \\
\text { ( } 75 \text { patients) }\end{array}$ & $\%$ & $P$ value \\
\hline age & & & & & & & & & 0.8665 \\
\hline$\leq 60$ years & 5 & 38,46 & 6 & 28,57 & 4 & 25,00 & 21 & 28,00 & \\
\hline$>60$ years & 8 & 61,54 & 15 & 71,43 & 12 & 75,00 & 54 & 72,00 & \\
\hline site of primary tumor & & - & & - & & - & & - & 0.3891 \\
\hline colon & 7 & 53,85 & 10 & 47,62 & 9 & 56,25 & 50 & 66,67 & \\
\hline rectum & 6 & 46,15 & 11 & 52,38 & 7 & 43,75 & 25 & 33,33 & \\
\hline primary tumor & & - & & - & & - & & - & 0.937 \\
\hline node + & 8 & 61,54 & 12 & 57,14 & 8 & 50,00 & 47 & 62,67 & \\
\hline node - & 5 & 38,46 & 9 & 42,86 & 8 & 50,00 & 27 & 36,00 & \\
\hline unknown & 0 & - & 0 & - & 0 & - & 1 & 1,33 & \\
\hline type of metastases & & - & & - & & - & & - & 0.6684 \\
\hline synchronous & 3 & 23,08 & 9 & 42,86 & 5 & 31,25 & 24 & 32,00 & \\
\hline metachronous & 10 & 76,92 & 12 & 57,14 & 11 & 68,75 & 51 & 68,00 & \\
\hline disease free interval & & - & & - & & - & & - & 0.0476 \\
\hline$\leq 12$ months & 1 & 7,69 & 8 & 38,10 & 5 & 31,25 & 18 & 24,00 & \\
\hline$>12$ months & 9 & 69,23 & 4 & 19,05 & 6 & 37,50 & 33 & 44,00 & \\
\hline CEA preoperative level & & - & & - & & - & & - & 0.0694 \\
\hline$\leq 50 \mathrm{ng} / \mathrm{ml}$ & 7 & 53,85 & 7 & 33,33 & 6 & 37,50 & 36 & 48,00 & \\
\hline$>50 \mathrm{ng} / \mathrm{ml}$ & 0 & - & 6 & 28,57 & 3 & 18,75 & 8 & 10,67 & \\
\hline unknown & 6 & 46,15 & 8 & 38,10 & 7 & 43,75 & 31 & 41,33 & \\
\hline tumor size & & - & & - & & - & & - & 0.8433 \\
\hline$\leq 5 \mathrm{~cm}$ & 11 & 84,62 & 18 & 85,71 & 14 & 87,50 & 65 & 86,67 & \\
\hline$>5 \mathrm{~cm}$ & 0 & - & 0 & - & 0 & - & 3 & 4,00 & \\
\hline unknown & 2 & 15,38 & 3 & & 1 & 6,25 & 8 & 10,67 & \\
\hline tumor number & & - & & - & & - & & - & 0.7004 \\
\hline single & 7 & 53,85 & 15 & 71,43 & 10 & 62,50 & 44 & 58,67 & \\
\hline multiple & 6 & 46,15 & 6 & 28,57 & 6 & 37,50 & 31 & 41,33 & \\
\hline number of metastases & & - & & - & & - & & - & 0.8278 \\
\hline$\leq 3$ lesions & 11 & 84,62 & 19 & 90,48 & 15 & 93,75 & 65 & 86,67 & \\
\hline$>3$ lesions & 2 & 15,38 & 2 & 9,52 & 1 & 6,25 & 10 & 13,33 & \\
\hline extent of liver resection & & - & & - & & - & & - & 0.8206 \\
\hline major hepatectomy & 6 & 46,15 & 8 & 38,10 & 8 & 50,00 & 29 & 38,67 & \\
\hline minor hepatectomy & 7 & 53,85 & 13 & 61,90 & 8 & 50,00 & 46 & 61,33 & \\
\hline
\end{tabular}

${ }^{*} \mathrm{p}$-value $=$ chi - squared test according to Pearson

scenario, margin re-resection to achieve R0 status does not improve long-term outcomes (20).

Makowiec F et al (2017), analysed 334 patients with first-time hepatic resection for isolated CLM. Thirty-two percent had neoadjuvant chemotherapy (targeted therapy in $42 \%$ ). According to the authors the hepatic margin status still remains the strongest independent prognostic factor. $(p<0.001)$. According to the authors this effect was also present after neoadjuvant chemotherapy for CRLM (21).
Sasaki K et al (2017) selected 630 patients who underwent CRLM resection, out of which 214 received bevacizumab. According to the authors the impact of margin status varied according to the receipt of bevacizumab (22).

Memeo P et al (2017) analysed 1784 hepatectomies from a multicentric retrospective cohort of hepatectomies. Primary tumour nodes found positive after colorectal resection $(p=0.02)$, operative time $(p=0.05)$, synchronous liver metastasis $(p=0.02)$, pedicle 
clamping (> $40 \mathrm{~min})(p=0.001)$, lesion size larger than 50 $\mathrm{mm}(p=0.001)$, rehepatectomy $(p=0.001)$, more than 3 lesions $(p=0.0001)$, and bilateral lesions $(p=0.0001)$ were identified as risk factors in multivariate analysis. R1 resection still remained a negative prognostic factor impacting overall and disease-free survival, with 1-, 3-, 5 -year OS at 94, 81, and $70 \%$ in RO and 92,75 , and $58 \%$ in $R 1$, respectively, $(p=0.008)$. R1 also negatively influenced and disease-free survival (DFS) with 1-, 3-, 5 -year survival of 64,41 , and $28 \%$ in R0 versus 51,28 , and $18 \%$ in R1 ( $p=0.0002)$, respectively. The authors conclude that R1 resection still impacts overall and disease-free survival negatively (23).

Detachment of CLMs from vessels has been proposed to prioritize parenchyma sparing and increase resectability.

Viganò $L$ et al (2016) evaluated the adequacy of R1 resections, analysing 627 resection areas in 226 consecutive patients. R1Parenchimal resection is not adequate for CLMs. Conversely R1Vascular (detachment from intrahepatic vessels) surgery achieves outcomes equivalent to RO resection (24).

\section{R0: which resection margin width?}

Some authors have emphasized the need to achieve a surgical margin greater than $1 \mathrm{~cm}$ during liver resection for CRLM. However, the results of these studies were often limited by the lack of a precise estimate of the width of the surgical margin when this was less than $1 \mathrm{~cm}(7-10)$.

Elias et al (1998) have shown that a free margin of just less than $1 \mathrm{~cm}$ did not have a significant impact on survival, although a trend existed for more prolonged survival with a margin of $3 \mathrm{~mm}$ to $9 \mathrm{~mm}$; in multivariate analysis, a powerful prognostic factor was a free margin greater than $9 \mathrm{~mm}$ (8).

Wray et al. (2005) evaluated 112 patients (67 men and 45 women) who underwent liver resection for colorectal metastases with negative margins. The authors divided patients into 3 groups $(0.5 \mathrm{~cm}, 0.5$ to 1 $\mathrm{cm}$ and $1 \mathrm{~cm}$ ) and demonstrated that the extent of the resection margin is a powerful prognostic factor after liver resection for CRLM (4).

Hamady et al. (2006) evaluated 293 consecutive patients who underwent primary liver resection for colorectal metastasis. They showed that the amplitude of the resection margin does not affect the percentage of postoperative recurrence and there was no significant difference in survival rates between patients with a margin of $1 \mathrm{~mm}$ and those with a margin of $\geq 2$ $\mathrm{mm}$. The authors state that the ' $1 \mathrm{~cm}$ rule' should be abandoned (18).
Muratore et al (2010) identified 314 patients who had undergone hepatectomy for CRM from a prospectively maintained institutional database (1/1999 - 12/2007).

In their study, the width of the negative resection margin $(\leq 1 \mathrm{~cm}$ versus $>1 \mathrm{~cm}$ ) was not a prognostic factor of worse RFS (30.2\% versus $37.3 \%, \mathrm{P}=0.6)$.

Node status of the primary tumour, as well as size and number of CRM were independent predictors of RFS. The authors conclude that tumour biology and not the width of the negative resection margin affect RFS (25).

More recently Postriganova N et al (2014) divided 155 eligible patients who underwent laparoscopic liver resections into 4 groups [Group 1, margins of $<1 \mathrm{~mm}$ ( $n=33$, including 17 patients with positive margins (Group 1a)]; Group 2, margins of $1 \mathrm{~mm}$ to $<3 \mathrm{~mm}$ ( $\mathrm{n}=$ 31); Group 3, margins of $\geq 3 \mathrm{~mm}$ to $<10 \mathrm{~mm}(\mathrm{n}=55)$, and Group 4, margins of $\geq 10 \mathrm{~mm}(\mathrm{n}=36)$. According to their data, patients with margins of $<1 \mathrm{~mm}$ achieved survival comparable with that in patients with margins of $\geq 10 \mathrm{~mm}$. When modern surgical equipment that generates an additional coagulation zone is applied, the association between resection margin and survival may not be apparent (26).

Angelsen $\mathrm{JH}$ et al (2014) published a combined retrospective (1998 to 2008) and prospective (2008 to 2010) cohort study of patients who underwent primary resection of CLM. Patients were stratified according to margin width; A: R1, <1 mm ( $\mathrm{n}=48,19 \%), \mathrm{B}: 1$ to $4 \mathrm{~mm}$ $(n=77), C: 5$ to $9 \mathrm{~mm}(n=46)$ and $D: \geq 10 \mathrm{~mm}(\mathrm{n}=71) . R 1$ resections for colorectal liver metastases predict adverse outcome. RMs below $5 \mathrm{~mm}$ increased the risk for LR and shortened the time to recurrence. Preoperative chemotherapy did not alter an adverse outcome in R1 vs. R0 patients (27).

Sadot $\mathrm{E}$ et al (2015) studied the relationship between resection margin and OS utilizing high-resolution histologic distance measurement. 2368 patients were included in the current study on total of 4915 liver resections were performed at Memorial Sloan Kettering Cancer Center between 1992 and 2012. R1 resection was defined as tumour cells at the resection margin $(0 \mathrm{~mm})$. $\mathrm{RO}$ resection was further divided into 3 groups: 0.1 to 0.9 $\mathrm{mm}, 1$ to $9 \mathrm{~mm}$, and $10 \mathrm{~mm}$ or greater. Resection margin width is independently associated with OS. The authors state that wide margins should be attempted whenever possible. However, resection should not be precluded if narrow margins are anticipated, as submillimeter margin clearance is associated with improved survival (28).

Margonis GA1,2 et al (2017) evaluated the impact of margin width on overall survival (OS) relative to KRAS 
status [wild type (wtKRAS) vs. mutated (mutKRAS)]. R1 resection was defined as margin clearance less than 1 $\mathrm{mm}$. R0 resection was further divided into 3 groups: 1$4,5-9$, and $\geq 10 \mathrm{~mm}$. While a 1-4 $\mathrm{mm}$ margin clearance in patients with wtKRAS tumors was associated with improved survival, wider resection width did not confer an additional survival benefit. In contrast, margin status, including a $1 \mathrm{~cm}$ margin, did not improve survival among patients with mutKRAS tumours (29).

These controversial results available in the literature may be explained by the fact that not all of these studies stratify patients according to the width of the resection margin (when this was less than $1 \mathrm{~cm}$ ) with a high resolution measure. Moreover, not all these studies specifyied or compared different methods of liver parenchyma dissection, not all included multivariate analyses, not all distinguished relapse recurrences at the resection margin and relapsed at other intrahepatic site. Often they also did not include other adverse biological factors that may have influenced the prognosis (17-19).

The present study evaluates prognosis after hepatic resection according to the 4 different margin width classes. In our experience the percentage of patients with a positive resection margin (resection R1) is $3.84 \%$; within this group the overall survival rates and 5 -years disease free survival rates are 0 (tables $2 a-b$ ).

In the univariate analysis, the reduced width of the surgical margin was significantly associated with a lower overall survival rate, together with the older age of 60 , synchronous metastases and multiple tumours. (table 2 a)

Moreover, in our experience, the reduced width of the surgical margin, rectal cancer, synchronous metastases and tumour number were significantly associated with a worse 5-year disease-free survival rate (table $2 b$ ).

Patients in the present study were operated with the aim to obtain, whenever possible, a tumour free margin greater than or equal to $1 \mathrm{~cm}$. However, the inability to achieve a margin of $1 \mathrm{~cm}$ was not considered a contraindication to hepatic resection for CRLM.

Indeed, $57.69 \%$ of patients had a margin greater than or equal to $1 \mathrm{~cm}$, while in $38.46 \%$ of the patients a margin of less than $1 \mathrm{~cm}$ was achieved.

All clinical and pathological factors associated with the different margin dimensions were evaluated to more thoroughly verify the results obtained in the univariate analysis. Significant correlation has been demonstrated between the reduction of the diseasefree margin and the free interval of disease less than 12 months (defined as the period between the appearance of the primary tumour and the diagnosis of liver metastases) (table 3).

In this study, the width of the surgical margin is a powerful prognostic factor after hepatectomy for CRLM. A resection margin of less than $10 \mathrm{~mm}$ is associated with a higher risk of recurrence on the surgical margin, with a lower overall survival rate and disease-free survival rate.

One possible criticism of our study is that data are based on a multicentric retrospectively maintained database. Moreover we did not include all patients who had undergone hepatic resection for colorectal metastases in the study period. However, there was no selection of patients who could enter the study except of those excluded because follow up was lacking. It is conceivable that, due to the large number of patients, the study population is representative of our entire cohort of patients. One more criticism could be found in the multicentric sample of patients. Different surgeons may apply different techniques, different methods of liver parenchyma dissection and different sources of energy. One of the strengths of the study is that all patients included in this study had detailed revision of follow-up and almost all patients have imaging studies to document exactly the time and site of recurrence.

\section{CONCLUSION}

In conclusion, this study confirms that the extent of the resection margin is a powerful factor influencing prognosis after hepatectomy for CRLM. A resection margin of less than $10 \mathrm{~mm}$ is significantly associated with a higher risk of intra and extra-hepatic recurrence and less disease-free survival. These findings confirm that surgery is still the only valid therapeutic option for these patients. The impossibility of achieving a resection margin greater than or equal to $10 \mathrm{~mm}$ should not be considered as a contraindication to surgery. In fact, as shown in our analysis, the global survival and the 5 years free survival is related not only to the disease-free margin but also to other factors (age, type and number of metastases, the site of the primary tumour). Correct and well-planned surgical technique in a multidisciplinary strategy currently plays a major role. Maximising tumour shrinkage increases the chances of radical resection and this is the most important variable conditioning survival independently of other prognostic factors (30-36). Nowadays, in the era of FOLFOXIRI + bevacizumab, even secondary liver resections should be considered a chance of cure for a subgroup of metastatic colorectal cancer patients with unresectable liver-limited disease (37). 


\section{Author contributions}

Zanghì A, Cavallaro A, Di Vita M, Cardì F, Cappellani A designed the study. Zanghì A, Cavallaro A, Rapisarda $C$, Mongiovì $S$, Cappellani A collected the data; Zanghì A, Cavallaro A, Di Vita M, Cardì F, Lo Menzo E, and Cappellani A drafted the article; all authors critically reviewed the article, read and approved the contents.

\section{Conflicts of interest}

Authors state there are NO conflicts of interest in the manuscript, including financial, consultant, institutional and other relationships that might lead to bias or to a conflict of interest. The authors also declare they have no source of founding.

\section{Ethical policies}

The procedures involved in the redaction of the article, and in the collection of data were in accordance with the ethical standards of the responsible committee on human experimentation (institutional and national) and with the Helsinki Committee for Human Rights.

\section{REFERENCES}

1. Nuzzo G, Giuliante F, Ardito F, Vellone M, Giovannini I, Federico B, et al. Influence of surgical margin on type of recurrence after liver resection for colorectal metastases: a single-center experience. Surgery. 2008;143(3):384-93. doi: 10.1016/j.surg.2007.09.038. Epub 2007 Dec 21.

2. Angelsen JH, Horn A, Eide GE, Viste A. Surgery for colorectal liver metastases: the impact of resection margins on recurrence and overall survival. World J Surg Oncol. 2014 Apr 27;12:127. doi: 10.1186/1477-7819-12-127.

3. Stangl R, Altendorf-Hofmann A, Charnely RM, Scheele J. Factors influencing the natural history of colorectal liver metastases. Lancet. 1994:343(8910):1405-10.

4. Wray CJ, Lowy AM, Mathews JB, Park S, Choe KA, Hanto DW, et al The significance and clinical factors associated with a subcentimeter resection of colorectal liver metastases. Ann Surg Oncol. 2005; 12(5):374-80. Epub 2005 Mar 29.

5. Adam R, Pascal G, Azoulay D, Tanaka K, Castaing D, Bismuth H Liver resection for colorectal metastases: the third hepatectomy. Ann Surg. 2003;238(6):871-83; discussion 883-4.

6. Jaeck D, Bachellier P, Guiguet M, Boudjema K, Vaillant JC, Balladur $P$, et al. Long-term survival following resection of colorectal hepatic metastases: Association Francxaise de Chirurgie. Br J Surg. 1997; 84(7):977-80.

7. Ekberg H, Tranberg KG, Andersson R, Lundstedt C, Ha"gerstrand I, Ranstam J, et al. Determinants of survival in liver resection for colorectal secondaries. Br J Surg. 1986;73(9):727-31.

8. Elias D, Cavalcanti A, Sabourin JC, Pignon JP, Ducreux M, Lasser P. Results of 136 curative hepatectomies with a safety margin of less than $10 \mathrm{~mm}$ for colorectal metastases. J Surg Oncol. 1998; 69(2):88-93

9. Shirabe K, Takenaka K, Gion T, Fujiwara Y, Shimada M, Yanaga K, et al. Analysis of prognostic risk factors in hepatic resection for metastatic colorectal carcinoma with special reference to the surgical margin. Br J Surg. 1997;84(8):1077-80.

10. Cady B, Jenkins RL, Steele GD, Lewis WD, Stone MD, McDermott WV, et al. Surgical margin in hepatic resection for colorectal metastasis. Ann Surg. 1998;227(4):566-71.
11. Fuhrman GM, Curley SA, Hohn DC, Roh MS. Improved survival after resection of colorectal liver metastases. Ann Surg Oncol. 1995; 2(6):537-41.

12. Ohlsson B, Stenram U, Tranberg KG. Resection of colorectal liver metastases: 25-year experience. World J Surg. 1998;22(3):268-76; discussion 276-7

13. Hamady ZZR, Cameron IC, Wyatt J, Prasad RK, Toogood GJ, Lodge JPA. Resections margin in patients undergoing hepatectomy for colorectal liver metastasis: a critical appraisal of the $1 \mathrm{~cm}$ rule. Eur $\mathrm{J}$ Surg Oncol. 2006;32(5):557-63. Epub 2006 Apr 3.

14. Wei AC, Sandhu L, Devitt KS, Gagliardi AR, Kennedy ED, Urbach DR, et al. Practice patterns for the management of hepatic metastases from colorectal cancer: a mixed methods analysis. Ann Surg Oncol. 2013;20(5):1567-74. doi: 10.1245/s10434-012-2698-3. Epub 2012 Nov 3.

15. Van Cutsem E, Nordlinger B, Adam R, Köhne CH, Pozzo C, Poston $G$, et al. Towards a pan-European consensus on the treatment of patients with colorectal liver metastases. Eur J Cancer. 2006; 42(14):2212-21. Epub 2006 Aug 10.

16. Kokudo N, Miki Y, Sugai S, Yanagisawa A, Kato Y, Sakamoto Y, et al. Genetic and histological assessment of surgical margins in resected liver metastases from colorectal carcinoma. Arch Surg. 2002; 137(7):833-40.

17. Yamamoto J, Shimada K, Kosuge T, Yamasaki S, Sakamoto M, Fukuda $\mathrm{H}$. Factors influencing survival of patients undergoing hepatectomy for colorectal metastases. Br J Surg. 1999;86(3):332-7.

18. Hamady ZZR, Cameron IC, Wyatt J, Prasad RK, Toogood GJ, Lodge JPA. Resections margin in patients undergoing hepatectomy for colorectal liver metastasis: a critical appraisal of the $1 \mathrm{~cm}$ rule. Eur $\mathrm{J}$ Surg Oncol. 2006;32(5):557-63. Epub 2006 Apr 3.

19. Pawlik TM, Scoggins CR, Zorzi D, Abdalla EK, Andres A, Eng C, et al. Effect of surgical margin status on survival and site of recurrence after hepatic resection for colorectal metastases. Ann Surg. 2005; 241(5):715-22, discussion 722-4.

20. Margonis GA, Spolverato G, Kim Y, Ejaz A, Pawlik TM. Intraoperative surgical margin re-resection for colorectal liver metastasis: is it worth the effort? J Gastrointest Surg. 2015;19(4):699-707. doi: 10.1007/s11605-014-2710-2. Epub 2014 Dec 2.

21. Makowiec F, Bronsert P, Klock A, Hopt UT, Neeff HP. Prognostic influence of hepatic margin after resection of colorectal liver metastasis: role of modern preoperative chemotherapy. Int J Colorectal Dis. 2018;33(1):71-78. doi: 10.1007/s00384-017-2916-3. Epub 2017 Nov 2

22. Sasaki K, Margonis GA, Andreatos N, Wilson A, Weiss M, Wolfgang $C$, et al. Prognostic impact of margin status in liver resections for colorectal metastases after bevacizumab. Br J Surg. 2017;104(7): 926-935. doi: 10.1002/bjs.10510. Epub 2017 Mar 7.

23. Memeo R, de Blasi V, Adam R, Goéré D, Piardi T, Lermite E, et al. Margin Status is Still an Important Prognostic Factor in Hepatectomies for Colorectal LiverMetastases: A Propensity Score Matching Analysis. World J Surg. 2017 Sep 19. doi: 10.1007/s00268-017-4229-7.

24. Viganò L, Procopio F, Cimino MM, Donadon M, Gatti A, Costa G, et al. Is Tumor Detachment from Vascular Structures Equivalent to RO Resection in Surgery for Colorectal Liver Metastases? An Observational Cohort. Ann Surg Oncol. 2016;23(4):1352-60. doi: 10.1245/s10434-015-5009-y. Epub 2015 Dec 29.

25. Muratore A, Ribero D, Zimmitti G, Mellano A, Langella S, Capussotti L. Resection margin and recurrence-free survival after liver resection of colorectal metastases. Ann Surg Oncol. 2010; 17(5):1324-9. doi: 10.1245/s10434-009-0770-4. Epub 2009 0ct 22.

26. Postriganova N, Kazaryan AM, Røsok BI, Fretland Ț, Barkhatov L, Edwin B. Margin status after laparoscopic resection of colorectal liver metastases: does anarrow resection margin have an influence on survival and local recurrence? HPB (0xford). 2014;16(9):822-9. doi: 10.1111/hpb.12204. Epub 2013 Dec 6.

27. Angelsen JH, Horn A, Eide GE, Viste A. Surgery for colorectal liver metastases: the impact of resection margins on recurrence and overall survival. World J Surg Oncol. 2014;12:127. doi: 10.1186/1477-7819-12-127.

28. Sadot E, Groot Koerkamp B, Leal JN, Shia J, Gonen M, Allen PJ, et 
al. Resection margin and survival in 2368 patients undergoing hepatic resection for metastatic colorectal cancer: surgical technique or biologic surrogate? Ann Surg. 2015;262(3):476-85; discussion 483-5. doi: 10.1097/SLA.0000000000001427.

29. Margonis GA, Sasaki K, Andreatos N, Kim Y, Merath K, Wagner D, et al. KRAS Mutation Status Dictates Optimal Surgical Margin Width in Patients Undergoing Resectionof Colorectal Liver Metastases. Ann Surg Oncol. 2017;24(1):264-271. doi: 10.1245/s10434-016-56091. Epub 2016 Sep 30

30. Sasaki K, Morioka D, Conci S, Margonis GA, Sawada Y, Ruzzenente A, et al. The Tumor Burden Score: A New "Metro-ticket" Prognostic Tool For Colorectal Liver Metastases Based on Tumor Size and Number of Tumors. Ann Surg. 2018;267(1):132-141. doi: 10.1097/SLA.0000000000002064.

31. Spampinato MG, Arvanitakis M, Puleo F, Mandala L, Quarta G, Traisci D, et al. Totally laparoscopic liver resections for primary and metastatic cancer in the elderly: safety, feasibility and short-term outcomes. Surg Endosc. 2013;27(6):1881-6. doi: 10.1007/s00464012-2687-4. Epub 2012 Dec 18

32. Ragusa M, Statello L, Maugeri M, Majorana A, Barbagallo D, Salito $\mathrm{L}$, et al. Specific alterations of the microRNA transcriptome and global network structure in colorectal cancer after treatment with
MAPK/ERK inhibitors. J Mol Med (Berl). 2012;90(12):1421-38. doi: 10.1007/s00109-012-0918-8. Epub 2012 Jun 4.

33. Cappellani $A$, Zanghì $A$, Di Vita $M$, Cavallaro $A$, Piccolo $G$, Veroux $P$ et al. Strong correlation between diet and development of colorectal cancer. Front Biosci (Landmark Ed). 2013;18:190-8.

34. Cappellani A, Di Vita M, Zanghi A, Veroux P, Cavallaro A, Lo Menzo $E$, et al. Biological and clinical markers in colorectal cancer: state of the art. Front Biosci (Schol Ed). 2010 Jan 1;2:422-31.

35. Zanghì A, Piccolo G, Cavallaro A, Pulvirenti E, Lo Menzo E, Cardì F et al. A pilot study about the oncologic safety of colonic selfexpandable metal stents (SEMS) in obstructive colon cancer: is occlusion always better than "silent" perforation? Eur Rev Med Pharmacol Sci. 2016;20(24):5242-8.

36. Zanghì A, Cavallaro A, Piccolo G, Fisichella R, Di Vita M, Spartà D, et al. Dissemination metastasis after laparoscopic colorectal surgery versus conventional open surgery for colorectal cancer: a metanalysis. Eur Rev Med Pharmacol Sci. 2013;17(9):1174-84.

37. Cremolini C, Casagrande M, Aprile G, Bergamo F, Masi G, Moretto R $R$, et al. Efficacy of FOLFOXIRI plus bevacizumab in liver-limited metastatic colorectal cancer: A pooled analysis of clinical studies by Gruppo Oncologico del Nord Ovest. Eur J Cancer. 2017;73:74-84. doi: 10.1016/j.ejca.2016.10.028. Epub 2016 Dec 13. 